\title{
The effect of skin permeation enhancers on the formation of porphyrins in mouse skin during topical application of the methyl ester of 5-aminolevulinic acid
}

\author{
Andrzej Bugaj ${ }^{\text {a,b,* }}$, Asta Juzeniene ${ }^{\text {b }}$, Petras Juzenas ${ }^{\text {b }}$, Vladimir Iani ${ }^{\text {b }}$, Li Wei Ma ${ }^{\text {, }}$, \\ Johan Moan ${ }^{\mathrm{b}, \mathrm{c}}$ \\ a Department of Clinical Pharmacy and Biopharmacy, Karol Marcinkowski University of Medical Sciences, ul. Marii Magdaleny 14, 61861 Poznań, Poland \\ ${ }^{\mathrm{b}}$ Department of Radiation Biology, Institute of Cancer Research. The Norwegian Radium Hospital, Oslo 0310, Norway \\ ${ }^{\mathrm{c}}$ Institute of Physics, University of Oslo, Oslo 0316, Norway
}

Received 20 July 2005; received in revised form 23 November 2005; accepted 9 December 2005

Available online 26 January 2006

\begin{abstract}
The influence of skin permeation enhancers, such as dimethyl sulphoxide (DMSO) and 1-[2-(decylthio)ethyl]azacyclopentan-2-one (HPE-101), Labrafac ${ }^{\circledR} \mathrm{CC}$, Labrafil ${ }^{\circledR}$, Labrasol ${ }^{\circledR}$ and Transcutol ${ }^{\circledR}$ in a concentration of $10 \%$ (wt./wt.) on the formation of porphyrins in normal mouse skin from topical application of creams with methyl 5-aminolevulinate (MAL) was studied. The concentration of porphyrins in the mouse skin was determined by direct fluorescence measurements. The results show that studied permeation enhancers increase the formation of porphyrins, and therefore also the skin penetration 2\% MAL whereas for 10\% and 20\% (wt./wt.) MAL concentrations only DMSO, HPE-101 and Labrafac ${ }^{\circledR} \mathrm{CC}$ increased the porphyrin formation. At all studied MAL concentrations DMSO gave the largest enhancing effect, similarly to that of HPE-101. This suggests that in 2-20\% MAL creams HPE-101 may be substituted by Labrafac ${ }^{\circledR} \mathrm{CC}$ to reduce skin irritation induced by HPE-101 without impairing the porphyrin formation.
\end{abstract}

(c) 2005 Elsevier B.V. All rights reserved.

Keywords: Porphyrins; Normal mouse skin fluorescence; In vivo direct skin fluorescence measurement; Methyl 5-aminolevulinate; Topical application; Permeation enhancers

\section{Introduction}

The 5-aminolevulinic acid (ALA), the precursor of porphyrin biosynthesis, is applied for fluorescence diagnosis and photodynamic therapy (PDT) of skin cancers [1-3]. The use of ALA has several advantages over traditional PDT, where photosensitizing dyes are injected intravenously or given orally. Firstly, ALA can be applied topically because it is small enough to penetrate the stratum corneum. Secondly, ALA-induced porphyrins are eliminated more rapidly from the organism than other sensitiz-

\footnotetext{
* Corresponding author. Tel./fax: $+48618529057 \times 55$.

E-mail address: andrzejbugaj@yahoo.fr (A. Bugaj).
}

ers, and therefore gives shorter lasting cutaneous photosensitization [1-3].

A limitation of ALA-PDT is the shallow penetration of ALA into tissues. Thus, ALA esters, which are more lipophilic than ALA, were introduced to PDT to get a deeper penetration and facilitate the treatment of larger tumors $[4,5]$. In some cases so-called penetration enhancers are added to ALA and its esters formulations [6-10].

In the present work, the influence of selected skin permeation enhancers on porphyrin formation from ALA esters was studied. The concentration of porphyrin formed is supposedly a measure of methyl ALA ester (5-aminolevulinate, MAL) penetration. Direct in vivo fluorescence measurements were used to determine the porphyrin concentration in the upper tissue layers. 


\section{Materials and methods}

\subsection{Chemicals}

MAL was purchased from Sigma Chemical Co. (St. Louis, MO). HPE-101 was a gift from Hisamitsu Pharmaceuticals (Tokyo, Japan). Labrafac ${ }^{\circledR} \mathrm{CC}$, Labrafil ${ }^{\circledR}$, Labrasol $^{\circledR}$ and Transcutol ${ }^{\circledR}$ were kindly supplied from Gattefossé (Saint Priest, France). All other reagents and solvents were of analytical grade and were used as purchased.

\subsection{Animals}

Inbred female albino nude mice (BALB/c, Norwegian Radium Hospital, Oslo, Norway) were used. The mice experiments were performed according to the European Convention for the Protection of Vertebrates Used for Scientific Purposes at the Norwegian Radium Hospital (Oslo, Norway) with ethical approval from the National Animal Research Authority.

\subsection{Fluorescence measurement}

A fiber-optic probe was coupled to a Perkin-Elmer LS50B luminescence spectrometer (Norwalk, CT) for in vivo fluorescence measurements. The probe was made of a commercially available fiber accessory (PerkinElmer, two $1 \mathrm{~m}$ fused silica fiber bundles joined in parallel at the measuring tip) fitted with a cylinder shaped aluminum spacer. This spacer was $6.5 \mathrm{~mm}$ in diameter and provided a constant, fixed distance of $10 \mathrm{~mm}$ between the fibers and the tissue. This assured a relatively uniform light distribution over the measuring area and provided the maximum fluorescence signal for a given sample. Fluorescence intensity was measured at the application site as a function of time. The excitation wavelength was set at $407 \mathrm{~nm}$ and fluorescence was measured at $636 \mathrm{~nm}$. The $407 \mathrm{~nm}$ light from the spectrometer was of low intensity $\left(1.5 \mu \mathrm{W} / \mathrm{cm}^{2}\right)$ and did not induce photobleaching.

\subsection{Application of $M A L$}

Prior to application of MAL, the animals were anesthesized intraperitonneally with Equithesin ${ }^{\circledR}$ (Rikshospitalet, Oslo, Norway) or by inhalation of Fluothane (Cyphrane Ltd. Keighley, Yorkshire, United Kingdom). Creams containing MAL were prepared in the standard ointment (Unguentum Merck, Germany). Approximately $0.1 \mathrm{~g}$ of the cream was applied to one flank of the mice. The application site ( $1 \mathrm{~cm}$ of diameter) was covered with an adhesive dressing (opSite Flexigrid, Smith and Nephew Medical Ltd., Hull, England) during the whole application period. Application of the cream was performed under different conditions for different groups, three animals per data point.

\subsection{Continous application}

MAL cream was applied with concentration $2 \%, 10 \%$ or $20 \%$ (wt./wt.). Fluorescence measurements were performed up to $24 \mathrm{~h}$. The fluorescence could be measured through the transparent occlusion tape, because the absorbance by the tape was negligible.

\subsection{Effect of skin permeation enhancers}

In the control group, creams containing $2 \%, 10 \%$ or $20 \%$ (wt./wt.) MAL without enhancer was applied. To six groups, were treated with creams containing $2 \%, 10 \%$ or $20 \%$ (wt./wt.) MAL supplemented with $10 \%$ (wt./wt.) of DMSO, HPE-101, Labrafac ${ }^{\circledR} \mathrm{CC}$, Labrafil ${ }^{\circledR}$, Labrasol ${ }^{\circledR}$ or Transcutol ${ }^{\circledR}$ were applied. The fluorescence was measured as described above [6].

\section{Results and discussion}

After application of creams containing 10\% of DMSO, HPE-101 or Labrafac ${ }^{\circledR} \mathrm{CC}$ an increase of porphyrin fluorescence was observed for all studied MAL concentrations, suggesting that these permeation enhancers increase bioavailability of MAL to the mouse skin. As shown in the Fig. 1a, the maximum fluorescence of $2 \%$ MAL in the presence of DMSO or HPE-101 was reached at about $6 \mathrm{~h}$, and its value was about 1.7-times higher than that in the control sample.

When MAL was applied at a concentration of $10 \%$ (wt./wt.), the porphyrin formation was the best in the presence of $10 \%$ (wt./wt.) DMSO. In this case the maximum of fluorescence was observed at about $5 \mathrm{~h}$. As for $2 \%$ MAL it was about 1.7-times higher than that of the control sample. For HPE-101 and Labrafac ${ }^{\circledR} \mathrm{CC}$ these maxima were respectively 1.5 - and 1.3 -fold higher that of the control (Fig. 1b). Similarly, in the case of $20 \%$ (wt./wt.) MAL cream, the enhancers in concentration $10 \%$ increased the porphyrin formation in a similar manner as for the creams with 10\% MAL (Fig. 1c). For all studied enhancers the fluorescence maxima were reached at about $5 \mathrm{~h}$.

Surprisingly, in the case of creams supplemented with $10 \%$ of Labrafil ${ }^{\circledR}$, Labrasol ${ }^{\circledR}$ or Transcutol ${ }^{\circledR}$ an increase of porphyrin formation, compared to that in the control sample without enhancers, was observed only for $2 \%$ MAL (Fig. 1a). For higher concentrations of MAL Labra$\mathrm{fil}^{\circledR}$ gave no significant effect on porphyrin formation while Labrasol $^{\circledR}$ and Transcutol ${ }^{\circledR}$ inhibited the formation significantly ( $1 \mathrm{~b}$ and $\mathrm{c})$. These phenomena are difficult to explain. Especially, the difference between effect of Labra$\mathrm{fac}^{\circledR} \mathrm{CC}$ and other enhancers is a challenging question. The reason for this difference may be differences in the mechanism of action. Labrafac ${ }^{\circledR} \mathrm{CC}$ (a mixture of medium-chain triglycerides) probably acts as a stratum corneum emollient [11-16], similarly to DMSO $[9,10,12]$ and HPE-101 $[6,12,17,18]$, while Labrafil ${ }^{\circledR}$, Labrasol ${ }^{\circledR}$ and 

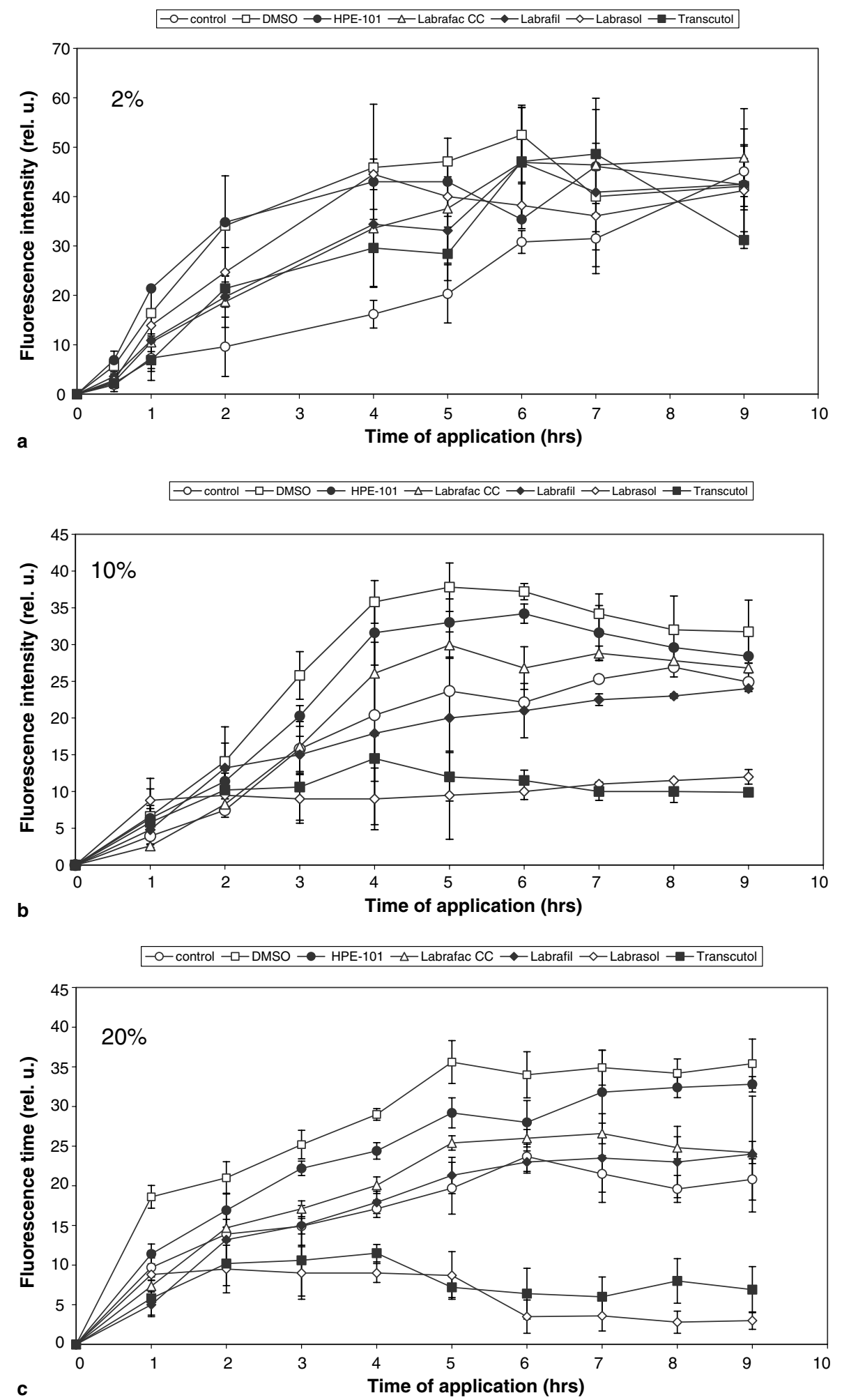

Fig. 1. In vivo porphyrin fluorescence kinetics in nude mouse skin after topical application of MAL $2 \%$ (a) $10 \%$ (b) $20 \%$ (c) in creams containing $10 \%$ of skin permeation enhancers. The control sample was MAL creams without any permeation enhancers. The data prints show the mean from three measurements. Error bars indicate the standard deviation.

Transcutol $^{\circledR}$ (containing ethylene glycol ethers and esters) act rather as emulsifiers and solubilizers of MAL $[11,13,19,20]$, so that their activity would be limited by a ratio of drug and cream basis concentrations $[11,20]$. On the other hand, the effects of these substances observed for $10 \%$ and $20 \%$ MAL did not change with increasing concentration (Fig. 1b and c). Thus, no firm conclusion concerning mechanisms can be drawn. 
In conclusion, our results demonstrate significant effects of penetration enhancers on the time-dependent kinetics of MAL induced porphyrins in tissues. The porphyrin production in the skin after application of $2 \%, 10 \%$ and $20 \%$ (wt./wt.) MAL creams do not depend on the concentration of MAL suggesting that the heme pathway of porphyrin metabolism is saturated [6]. Ten percent (wt./wt.) DMSO, HPE-101 and Labrafac ${ }^{\circledR} \mathrm{CC}$ increased the penetration of MAL into intact mouse skin. The similarity of the effects of Labrafac ${ }^{\circledR} \mathrm{CC}$ and HPE-101 suggests that by Labrafac ${ }^{\circledR} \mathrm{CC}$ would be a good alternative for HPE-101 in the MAL creams, since it may give less skin irritation than HPE-101. A surprising and yet not understood effect was the decrease of porphyrin formation observed after application of Labrasol ${ }^{\circledR}$ and Transcutol ${ }^{\circledR}$.

\section{Abbreviations}

ALA 5-aminolevulinic acid

DMSO dimethyl sulfoxide

HPE-101 1-[2-(decylthio)ethyl]azacyclopentan-2-one

MAL methyl 5-aminolevulinate

PDT photodynamic therapy

wt./wt. weight/weight concentration

\section{References}

[1] J.C. Kennedy, S.L. Marcus, R.H. Pottier, Photodynamic therapy (PDT) and photodiagnosis (PD) using endogenous photosensitization induced by 5 -aminolevulinic acid (ALA): mechanism and clinical results, J. Clin. Laser Med. Surg. 14 (1996) 289-304.

[2] Q. Peng, T. Warloe, K. Berg, J. Moan, M. Kongshaug, K.E. Giercksky, J.M. Nesland, 5-aminolevulinic acid-based photodynamic therapy. Clinical research and future challenges, Cancer 79 (1997) 2282-2308.

[3] Q. Peng, K. Berg, J. Moan, M. Kongshaug, J.M. Nesland, 5aminolevulinic acid-based photodynamic therapy: principles and experimental research, Photochem. Photobiol. 65 (1997) 235-251.

[4] Q. Peng, J. Moan, T. Warloe, V. Iani, H.B. Steen, A. Bjørseth, J.M. Nesland, Build-up of esterified aminolevulinic-acid-derivativeinduced porphyrin fluorescence in normal mouse skin, J. Photochem. Photobiol. B 65 (1997) 235-251.

[5] J. Moan, L.W. Ma, A. Juzeniene, V. Iani, P. Juzenas, F. Apricena, Q. Peng, Pharmacology of protoporphyrin IX in nude mice after application of ALA and ALA esters, Int. J. Cancer 103 (2003) 132-135.

[6] J. van den Akker, V. Iani, W. Star, H.J.C.M. Sterenborg, J. Moan, Topical application of 5-aminolevulinic acid to normal nude mouse skin: differences in protoporphyrin IX fluorescence kinetics and the role of the stratum corneum, Photochem. Photobiol. 72 (2000) 681-689.

[7] P. Ziółkowski, B.J. Osiecka, G. Oremek, M. Siewiński, K. Symonowicz, Y. Saleh, A. Bronowicz, Enhancement of photodynamic therapy by use of aminolevulinic acid/glycolic acid drug mixture, J. Exp. Ther. Oncol. 4 (2004) 21-129.

[8] Y. Harth, B. Hirshowitz, B. Kaplan, Modified topical photodynamic therapy of superficial skin tumours, utilizing aminolevulinic acid, penetration enhancers, red light and hyperthermia, Dermatol. Surg. 24 (1998) 723-726.

[9] F.S. de Rosa, R.F.V. Lopez, J.S. Thomazini, A.C. Tedesco, N. Lange, M.V.L.B. Bentley, In vitro metabolism of 5-ALA esters derivatives in hairless mice skin homogenate and in vivo PPIX accumulation studies, Pharm. Res. 21 (2004) 2247-2252.

[10] A. Casas, C. Perotti, H. Fukuda, L. Rogers, A.R. Butler, A.M.C. Batlle, ALA and ALA hexyl ester induced porphyrin synthesis in chemically induced skin tumors: the role of different vehicles on improving photosensitization, Br. J. Cancer 85 (2001) 1794-1800.

[11] R.G. Strickley, Solubilizing excipients in oral and injectable formulations, Pharm. Res. 21 (2004) 201-230.

[12] A.C. Williams, B.W. Barry, Penetration enhancers, Adv. Drug Deliv. Rev. 56 (2004) 603-618.

[13] H.J. Kim, K.A. Yoon, M. Hahn, E.S. Park, S.C. Chi, Preparation and in vitro evaluation of self-microemulsifying drug delivery systems containing idebenone, Drug Dev. Ind. Pharm. 26 (2000) $523-529$.

[14] T.R. Kommuru, B. Gurley, M.A. Khan, I.K. Reddy, Self-emulsifying drug delivery systems (SEDDS) of coenzyme Q10: formulation, development and bioavailability assessment, Int. J. Pharm. 212 (2001) $233-246$.

[15] I. Minkov, T. Ivanova, I. Panaiotov, J. Proust, P. Saulnier, Reorganization of lipid nanocapsules at air-water interface Part 2. Properties of the formed surface film, Colloids Surf. B Biointerfaces 44 (2005) 97-203.

[16] I. Minkov, T. Ivanova, I. Panaiotov, J. Proust, R. Verger, Reorganization of lipid nanocapsules at air-water interface Part 3. Action of hydrolytic enzymes HLL and pancreatic PLA(2), Colloids Surf. B Biointerfaces 45 (2005) 24-34.

[17] T. Yano, K. Furukawa, M. Tsuji, K. Noda, M. Otagiri, Evaluation of a new penetration enhancer 1-[2-(decylthio)ethyl]azacyclopentan-2one (HPE-101), J. Pharmacobiodyn. 155 (1992) 27-533.

[18] T. Yano, N. Higo, K. Fukuda, M. Tsuji, K. Noda, M. Otagiri, Further evaluation of a new penetration enhancer, HPE-101, J. Pharm. Pharmacol. 45 (1993) 775-778.

[19] Q. Zhang, X. Jiang, W. Jiang, W. Lu, L. Su, Zh. Shi, Preparation of nimodipine-loaded microemulsion for intranasal delivery and evaluation on the targeting efficiency to the brain, Int. J. Pharm. 275 (2004) $85-96$.

[20] T.M. Hsu, E. Jacobson, R.C. LoBello, E.C. Luo, Dual enhancer composition for topical and transdermal drug. US Patent no. 6835392: 2004. 